\title{
Word Order Patterns in Greek Nominals: Aspects of Diachronic Change'
}

\author{
Artemis Alexiadou \\ University of Potsdam \\ artemis@ling.uni-potsdam.de
}

\begin{abstract}
In this paper I investigate a change in the word order patterns of Greek nominalizations that took place from the Classical Greek (CG) period to the Modern Greek (MG) one. Specifically, in CG both the patterns in (A), with its two subtypes, and (B) were possible; the MG system, on the other hand, exhibits only the (B) pattern. The difference between the two systems is that agents can only be introduced in the form of prepositional phrase in MG nominals in a position following the head noun, while they could appear in a prenominal position bearing genitive case in CG. Moreover, the theme genitive, i.e. the objective genitive, could precede the head nominal in CG; this is no longer the case in MG, where the theme genitive follows the head noun obligatorily:
\end{abstract}

(A) i) Det-(Genagent)-Nprocess-Gentheme / ii) Det-Gentheme-Nprocess

(B)Det-Nprocess-Gentheme (PPagent)

I argue that the unavailability of (A) in $M G$ is linked to the nature and the properties associated with a nominal functional projection contained within process nominals and to other related changes in the nominal system of Greek.

\section{The problem: argumental genitives in the history of Greek}

In MG the agent of a process nominal surfaces obligatorily as a PP (1a):

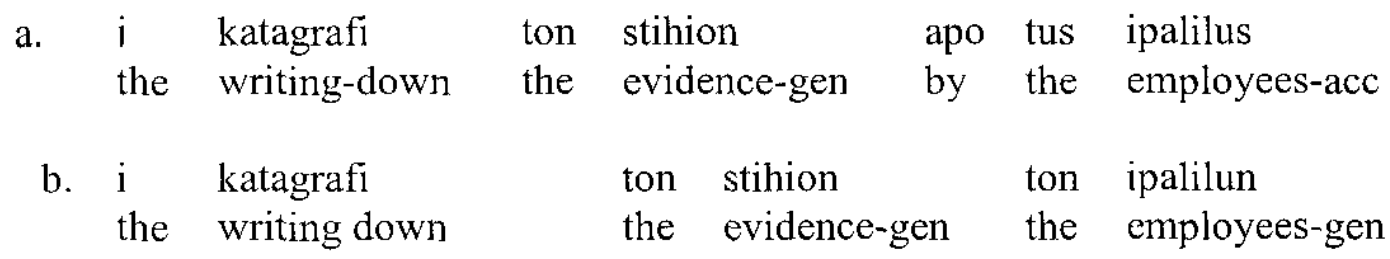

(1b) is impossible on the reading that (1a) has, i.e. 'the employees were the ones that wrote the evidence down'. The sentence is fine if the second genitive is interpreted as the possessor of the object, i.e. the evidence that belongs to the employees. Moreover, (1a) is the only possible order the arguments of the noun can surface in. The examples in (2), where either the genitive or the PP appear in prenominal position, are both ungrammatical:

$\begin{array}{lllll}\text { (2) a. } & *_{\mathrm{i}} & \text { ton stihion } & \text { katagrafi } & \text { apo tus ipalilus } \\ \text { the } & \text { the evidence-gen } & \text { writing down } & \text { by the employees-acc }\end{array}$

\footnotetext{
' Preliminary versions of this paper were presented at the workshop on Nominalization at the University of Tübingen in April 2001, and at the workshop on DP-internal relations at the University of Thessaloniki in September 2001. I would like to thank the participants for their comments. Many thanks to Jane Grimshaw, Melita Stavrou and Ilse Zimmermann for discussions.
} 
b. $*_{\mathrm{i}}$ apo tus ipalilus
the by the employees-acc

Note that fronting of the argumental genitive is possible, resulting in focalization of the fronted argument (cf. Horrocks \& Stavrou 1987):
(3) ton stihion
i katagrafi
apo tus ipalilus
the evidence-gen the writing down
by the employees-acc

CG differs from MG in the following ways. First, alongside with (4), the MG pattern, two genitives signaling different relations to the same noun were possible, see (5)-(7):

(4) $\mathrm{h}$ men empempsis ths stratias hupo Lakedaimonio_n

the prt sending the army-gen by Spartans-gen

'the sending of the army by the Spartans' Th. 4.85.1

(5) thn ge emfrono_n zhthsin tou mellontos

the prt wise-gen search the future-gen

'the search of the future by the wise ones' Pl. Phrd. 224c

(6) hê Phaia_kôn proenoikêsis tês Kerku_ra_s

the-nom Phaecians-gen occupation-nom the-gen Corcyra-gen

'the Phaeacians' occupation of Corcyra' T. 1.25.

(7) hê tou Lachêtos tôn neôn archê

the-nom Laches-gen the fleet-gen command-nom

'Laches' command of the fleet' $\quad$ T. 3.115

Second, while in MG the objective genitive cannot precede the noun, cf. (2a), this was possible in $\mathrm{CG}$ :

(8) th to_n echthro_n timo_rian

the the enemies-gen punishment-acc Lys. 2.16

In CG even PPs (9) and adverbs could appear in pre-nominal, post-determiner position, as reported in Manolessou (2000). This is no longer possible in Modern Greek, cf. (2b) and (10):
(9) ai es thn Attikhn the into Attica
esbolai Peloponnhsio_n
invasions Peloponnesians-gen
(10) $* \mathrm{i}$ ktes katastrofi tis polis
the yesterday destruction the city-gen
$C G$
$M G$

Before I entertain a hypothesis concerning the CG patterns, the following remarks are in order. The examples in (5)-(6) seem reminiscent of certain nominal constructions found in other languages. These are shown in (11). (11a) is a transitive nominalization in English. (11b) is a similar construction in Russian containing a possessive adjective (PA) in the function of the agent, and (11c) is a transitive nominalization in Italian, where the agent again appears in the form of the possessive adjective: 
(11) a. the barbarian's destruction of the city

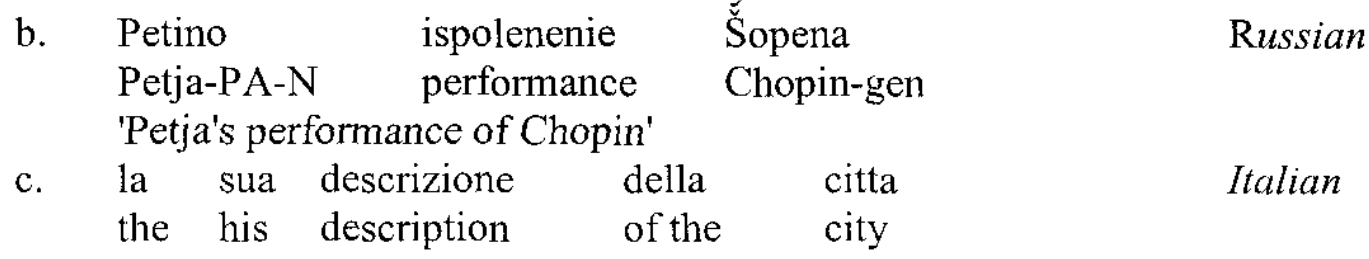

(8) seems similar to passive nominalizations in English illustrated in (12):

the city's destruction

Since MG lacks all these patterns, the question that arises is whether the CG patterns could receive a similar analysis to that of (11)-(12). Thus it could be the case that whatever accounts for the difference between $\mathrm{MG}$ and the other languages is responsible for the differences between MG and CG. However, matters are not that simple. As we will see, the change observed is a result of various morpho-syntactic factors affecting the functional domain within process nominals, and it cannot be straightforwardly attributed to the factors causing MG nominals to differ from e.g. their English counterparts.

The paper is structured as follows. In section 2 I present my assumptions concerning the structure for process nominals. In section 3 I outline a way to deal with synchronic variation among language and types of nominalizations, showing that these reduce to properties of functional projections inside the DP. Finally, in section 4 I offer a journey through the history of Greek nominalizations. I associate the differences between MG and CG to properties of a functional projection, labeled FP in section 3. The changes are further related to other morpho-phonological changes within the Greek DP.

\section{The structure of process nominals}

It is typically assumed that there is a small number of primitive, universal grammatical categories: $\mathrm{N}$ (noun), $\mathrm{V}$ (verb), A (adjective) and $\mathrm{P}$ (preposition). Each is taken to have a number of prototypical/distinct properties. Consider verbs as opposed to nouns. Their prototypical properties are listed in Table 1, as well as the range of inflectional elements they are associated with.

\section{Table 1}

\begin{tabular}{|l|l|}
\hline \multicolumn{1}{|c|}{ Verbs } & \multicolumn{1}{|c|}{ Nouns } \\
\hline denote events & are referential expressions \\
\hline take arguments (participants in the event) & lack arguments (participants in the event) \\
\hline $\begin{array}{l}\text { are modified by adverbs } \\
\text { inflect for tense, aspect, voice, mood, } \\
\text { agreement }\end{array}$ & $\begin{array}{l}\text { are modified by adjectives } \\
\text { iefiniteness }\end{array}$ \\
\hline
\end{tabular}

Derived nominals ${ }^{2}$ however, belong to a class of constructions referred to as trans-categorial or simply mixed category constructions, which do not fit well with the basic distinction in categories. These constructions involve elements that seem to be core members of more than one category simultaneously. Specifically, although they have the distribution of other common nouns, they retain verbal properties. For instance, derived nominals typically occur in

\footnotetext{
${ }^{2}$ Here I refer only to process nominals. For further discussion, see Grimshaw (1990) and Alexiadou (2001).
} 
positions that generally admit nouns (13), but they seem to bear the same semantic relations to the NPs that accompany them as their related verbs do; non-deverbal nominals, e.g. book, do not have such properties (14).

(13) a. Why does John's criticizing the book/John bother you?

b. I believe that many authors wrote about the destruction of the city/human rights

(14) a. John criticized the book

b. The barbarians destroyed the city

As argued for in detail in Alexiadou (2001), the verbal properties of nominals are accounted for by assuming that such nominals contain nominal as well as projections standardly associated with verbal clauses, namely vP and AspectP (Alexiadou 1999, 2001, van Hout \& Roeper 1998, Borer 1999). Nominals lacking such verbal properties also lack such verbal projections. Hence nominal properties are attributed to nominal functional layers, while verbal properties are attributed to verbal projections. In particular the structure in (15a), containing an AspectP and a vP, constitutes an eventive environment which can be embedded in multiple environments, e.g. participles, verbal clauses and process nominals. Nominals, as shown in (15b), contain further nominal functional projections, which are responsible for the nominal properties of process nominals. In fact these nominal projections determine the category of the word (see Alexiadou op.cit. for discussion). In case (15a) is embedded under $\mathrm{T}$, the result is a verbal clause.

(15) a.

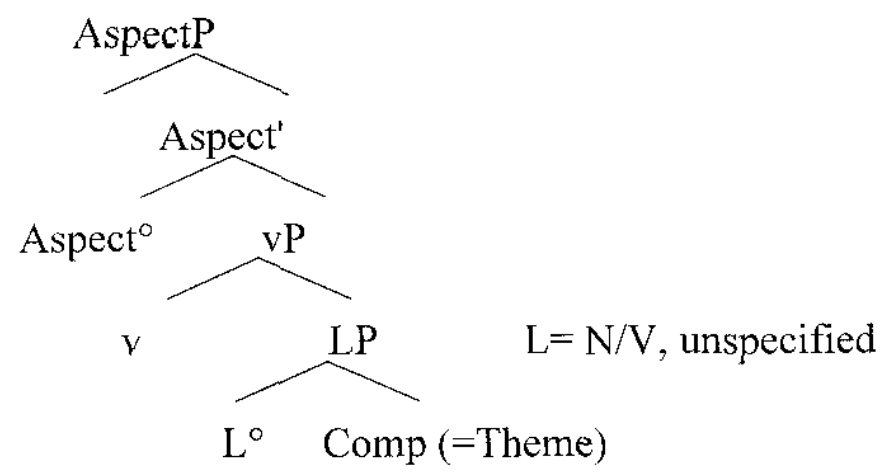

b.

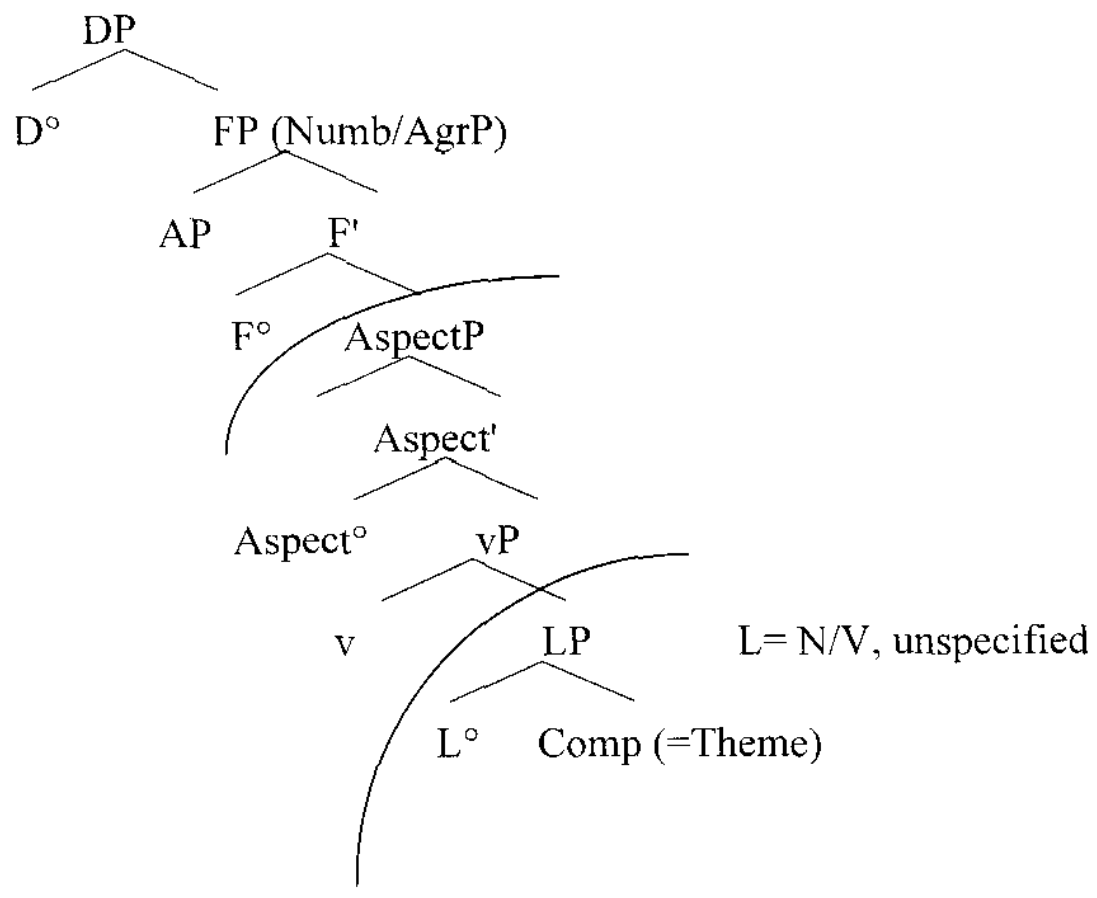


The functional heads in (15b) are associated with certain properties, briefly discussed here. In particular, D is the locus of definiteness. FP is a projection associated with gender/number (= nominal agreement) morphology (see section 3.2). The morphology of MG and CG nouns does not provide arguments for splitting these features in distinct projections. Rather noun endings are portmanteau morphemes, signaling number, gender and case (see Appendix). The verbal functional head $v$ (Kratzer 1994, Chomsky 1995) is the locus of agentivity, i.e. of features relevant to the licensing and interpretation of external arguments. It contains Case features for the object, and features related to eventivity. It comes in two types: one that introduces an external argument, and one that does not. Finally, the verbal functional head Aspect further specifies event presentation.

As argued for in detail in Alexiadou (2001), the presence of verbal projections within certain types of nominals accounts for the licensing of arguments, cf. also Borer (1999), their event reading, and the fact that they manifest aspectual distinctions associated with Aspect. Moreover, the presence of these functional projections also accounts for the licensing of certain types of adverbs within these nominals. As has been noted in the literature, manner, and aspectual (frequency, interval denoting) adverbs are acceptable, while modal and speakeroriented ones are not (cf. Borer 1993, Hazout 1995 for Hebrew, Alexiadou \& Stavrou 1998, Alexiadou 2001 for Greek among others). On the view that Aspectual adverbs are linked to an Aspect Phrase, while manner adverbs bear a tight relation to Voice Phrase (cf. Alexiadou (1997), Cinque (1999)), this distribution is explained. The lack of sentential adverbs is accounted for if the structure contains only a sub-section of the verbal clause and does not include projections like Tense, which are responsible for the licensing of 'higher' adverbs. Finally, in several languages there is an overt morphological reflex of Voice and Aspect, as in e.g. Turkish or Slavic languages (Alexiadou 1999, 2001 for further discussion).

In the system put forth in Alexiadou (2001) the variation found with nominalization types across languages and within a language depends on the type and the number of the verbal as well as of the nominal projections in (15b). In the next section, I give an illustration of this view.

\section{$3 \quad$ Variation in nominalizations}

The various types of nominals encountered across languages and within a language are accounted for in terms of variation depending on the number of functional projections included in the structure, i.e. whether both Aspect and $v$ are present or not and the type, i.e. the feature specification, of the verbal and nominal functional projections. On this view, the semantic-syntactic as well as morphological properties of the various constructions are determined by the height of attachment of the various morphemes. That is certain affixes include Aspect, e.g. -ing, while others lack all verbal-like projections, e.g. -ee. Since both verbal and nominal projections form a derived nominal, variation is dependent on both 'sets'.

The following two tables summarize the results of Alexiadou (2001). Table 2 summarizes the variation in the number of projections contained within nominals. Table 3 summarizes the results concerning the feature specification of $v$.

Table 2: variation depending on number of projections

\begin{tabular}{|l|l|l|}
\hline Type of Nominal & Language & Structure \\
\hline Nominalized Clause & Greek & D embeds CP \\
\hline Derived Nominals & Greek/Polish & D embeds AspectP \\
\hline Gerunds & English & D embeds AspectP \\
\hline -er nominals/certain derived ones & English/Greek/Russian & D embeds vP \\
\hline
\end{tabular}




\section{Table 3: variation depending on the type of $v^{3}$}

\begin{tabular}{|c|l|l|}
\hline$v$ & Language & Type of Nominal \\
\hline$+\mathrm{ag},-\operatorname{tr}$ & English & -er Nominals \\
\hline$+\mathrm{ag},+\operatorname{tr}$ & English & Gerunds \\
\hline$-\mathrm{ag},-\operatorname{tr}$ & Greek/Romance/Slavic & Destruction \\
\hline
\end{tabular}

For details the reader is referred to Alexiadou (2001).

The question that arises next is how we can use this system in order to deal with the word order change in Greek nominals. Given that the properties of CG nominals seem similar to that of MG nominals as far as the verbal part of the nominalization structure is concerned, I assume that $\mathrm{CG}$ nominal are also formed on the basis of (15a). Examples such as (4), repeated here, show that CG nominals are also 'passive':

$\begin{array}{lll}\text { (4) } h \text { men } & \text { empempsis } & \text { ths stratias } \\ \text { the } & \text { sending } & \text { the army-gen } \\ \text { det } & \text { Noun } & \text { Theme }\end{array}$

'the sending of the army by the Spartans'

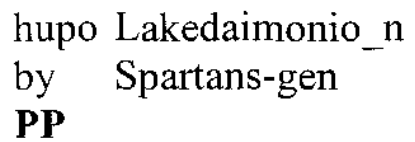

Th. 4.85 .1

In other words, both in $\mathrm{CG}$ and in MG nominals $\mathrm{v}$ is [-transitive] and do not introduce agents.

Recall the differences once more. CG nominals are like their MG counterparts in that the internal argument bears genitive and the agent is introduced by a PP, but differ in that they also permit constructions where the agent bears genitive and appears in prenominal position. In this respect they are like English 'transitive' nominalizations or their Romance/Slavic transitive nominalizations with possessive adjectives. The relevant data are repeated in (16).

(16) a. John's destruction of the city

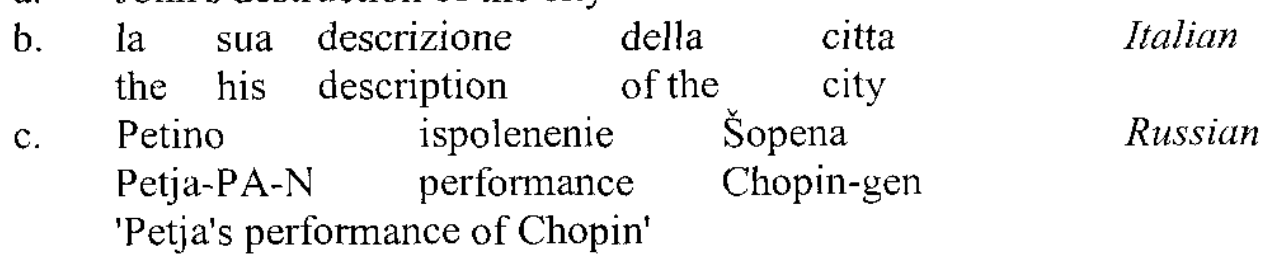

Moreover, CG nominals, like their English counterparts, permit passivization, i.e. prenominal placement of the objective genitive. In Alexiadou (2001) the availability of transitive as well as passive nominalizations in English was linked to the nominal part of the structure. I briefly summarize these findings in the next sub-section.

\subsection{Transitivity/Passivization depending on the status of Spec,DP}

In Alexiadou (2001) I argued that English nominalizations are transitive, not because $\mathrm{v}$ is [+tr] but because agents in these nominalizations are located in Spec,DP, which is an Aposition in English (Abney 1987). An argument in favor of analysing Spec,DP in English as an A-position is the fact that it does not tolerate expletives.

$$
\text { *there's destruction }
$$

In MG DP corresponds to CP, as argued for in detail in Horrocks and Stavrou (1987). Consider (18):

\footnotetext{
${ }^{3} \mathrm{ag}=$ agentive, $\mathrm{tr}=$ transitive.
} 
(18)
$\begin{array}{ll}\text { a. } & \text { kritiki } \\ \text { the review }\end{array}$
tu vivliu
the-gen book-gen
b. tu vivliu i kritiki

In the (b) example the interpretive effect of fronting is one of focalizing. This is reminiscent of the fronting of constituents that takes place in sentences for the purpose of bringing a particular constituent into prominence (see Tsimpli 1995):
edhose to vravio
tis
Afrodhitis
gave-3sg the prize-acc the-gen
Aphrodite-gen
'he gave the prize to Aphrodite'
b. tis Afrodhitis edhose to vravio
c. to vravio edhose tis Afrodhitis

(20) illustrates the interaction between $w h$-movement at the clausal level and DP-internal whmovement.

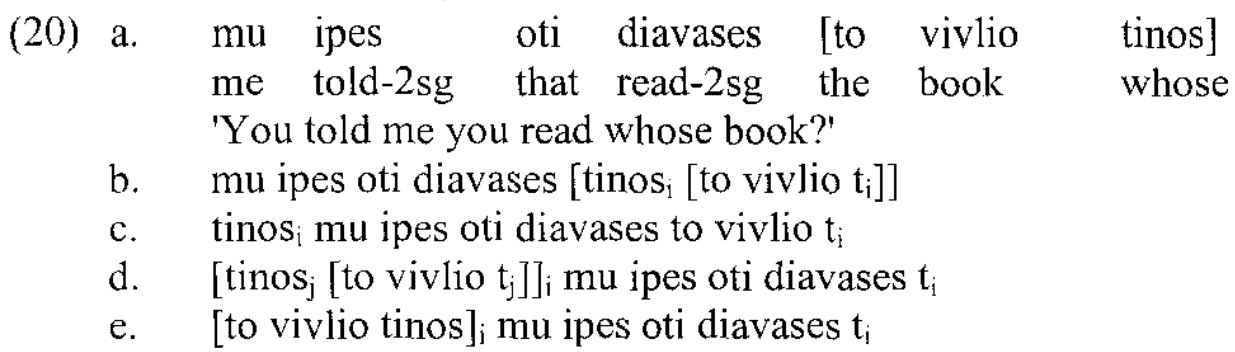

As a result, agents and as well as theme genitives can appear in pre-nominal position in English but not in Greek. Following Grimshaw (1990), I assumed that Spec,DP is not linked with any specific thematic role, i.e. it does not introduce agents only. Hence DPs other than agents can appear in this position.

Could we attribute the difference between CG and MG to the properties of Spec,DP? The answer is negative. The 'transitivity' of CG nouns cannot receive a similar explanation to the one just outlined for the transitivity of English nominalizations. Spec, DP is an A'-position in CG as well, see Taylor (1990). Moreover, the order of constituents is Det-Gen-N, suggesting that the genitive is not in Spec,DP. This is very similar to the situation we find in Slavic, where PAs follow demonstratives (21), which are assumed to be situated in Spec,DP:

$\begin{array}{lll}\text { (21) etu moju/Vasinu rabotu } & \\ \text { this mine/Vasja-PA } & \text { work }\end{array}$

In the next sub-section I entertain the hypothesis that the transitivity of CG nominalizations is related to the other nominal projection, namely FP.

\subsection{On the properties of FP}

Szabolcsi (1994), Ritter (1991), and Zribi-Hertz (1998) among others have argued that the FP in $(15 \mathrm{~b})$ is very similar to Infl; the labels attributed to this projection vary from author to author, Nominal Infl, Number or AgrP have all been suggested. On this view, FP is similar to IP introducing the subject of the verbal clause. It hosts possessors, which are taken to be like subjects of verbal clauses (22). For arguments that such a projection is present within Greek nominals as well, see the Appendix and the references in Alexiadou (2001): 
(22)

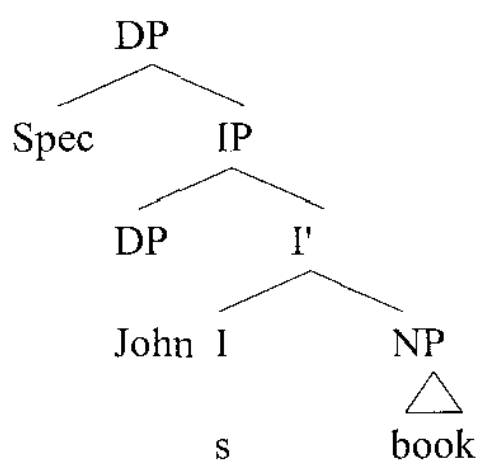

Empirical support for the suggested parallelism between possessors and subjects is given by the following Hungarian data. As (23b) shows, the possessed noun agrees with the possessor bearing nominative case in number and person, much like the subject agrees with the verb in (23a):
a. $\mathrm{Mi}$ iru
1pl-nom write-1pl
b. mi titku
1-pl-nom secret-sg-1p1

Recent literature also assumes that this FP is a projection in which possessors and 'nominal' agents are located. For instance, Schoorlemmer (1998) argues that possessors are situated in FP and in languages like English, where these do not-occur with determiners, they move to D. On the other hand, when they co-occur with determiners they remain situated in Spec,FP (cf. (24a vs. 24b) and Cardinaletti 1998 for prenominal possessors in Romance):

(24) a. [ip article [ip Possessor Fo [XP ]]]
a'. la
$\begin{array}{ll}\text { sua } & \text { casa } \\ \text { poss.adj } & \text { home }\end{array}$
b. [DP Possessor $\mathrm{D}^{\circ}[$ FP t toss Fo
$[\mathrm{XP}]]]$
b.' John's
book

Pesetsky \& Torrego (2000), like Schoorlemmer, assume that the prenominal genitive is in a lower position, but maintain that in English the D position remains empty.

$$
\text { [DP article [RP Mary [R } \mathrm{S} \text { [XP criticism of Sue ]]] }
$$

The above structures provide a way to account for the CG patterns, especially if one considers their properties and their development through time in more detail. I argue that the genitive in $\mathrm{CG}$, both the theme genitive as well as the agentive one in the transitive nominalization, are located in Spec,FP. MG can only host agreeing elements in this position for reasons that will be discussed in section 4 .

\section{The diachronic variation}

Recall the word order patterns once again.
(A) i) Det (Genagent)-Nprocess-Gentheme / ii) Det-Gentheme-Nprocess
(B) Det-Nprocess-Gentheme (PPagent) 
The two issues, namely the 'transitivity' and the internal position of the theme genitive are obviously related. That is the genitive, subjective or objective, occupies the same position in both instances of $(\mathrm{A})$.

In what follows I offer an answer to these two questions I examine the two patterns through the historical periods of the Greek language in order to determine when the (B) pattern became more frequent. Before doing that, I briefly summarize in section 4.1 the historical periods of the Greek language.

\subsection{Periods}

The Greek language is subdivided in the following periods:

(i) Ancient phase:

14th-6th century. This is subdivided into Mycenaean period (texts in syllabic script attested from the 14th/13th century BC to 8 th century) and Archaic (8th-6th century)
(ii) Classical phase:
5 th-4th centuries
(iii) Hellenistic and Roman phase: 4th century $\mathrm{BC}$ to 4th century $\mathrm{AD}$ (Koine)
(iv) Byzantine phase:
5 th to 15 th century $\mathrm{AD}$
(v) Modern phase:
15 th century AD to present day

Two things should be kept in mind: (a) Greek splits into several dialects, both Ancient and Modern (Ancient: Doric, Ioanian, Attic, Phocian etc, Modern: Pontic, Cypriot, Tsakonian, Cretan, Peloponnesian, Nothern, South Italian). I try to abstract away from such distinctions. (b) Very early on, the phenomenon of diglossia emerges (in Antiquity, Byzantium and modern period) i.e. two parallel registers/grammars exist, one that attempts to stay faithful to Classical Attic (especially in written form), and one that develops in a 'natural' way. The grammar of the learned written language changes very slowly, if at all (see the discussion in Horrocks 1997). Hence what is relevant for our discussion is the development of pattern (B) in the texts which do not follow the formal register.

Let me now consider the word order in Greek nominalizations through these periods in some detail.

\subsection{Word order patterns from Homer to $\mathbf{M G}^{4}$}

In Homeric Greek there is not much clear evidence with respect to the word order patterns, since both GN and NG occur. At this stage, it is not clear which one of the two is the basic order, since both could be derived. The reason for this is that the definite article was used as a demonstrative pronoun in Homer, and only in CG did it develop to a definite article, as we know it from MG.

In $\mathrm{CG}$, as has been already mentioned, both (A) and (B) are found. In fact, there is more variation. When only one genitive is present, it surfaces in the following positions:

(I) Det-N-Gen, cf. (4):

(26) h men empempsis ths stratias the sending the army-gen 'the sending of the army by the Spartans' hupo Lakedaimonio_n

by Spartans-gen

Th. 4.85.1

(II) Gen-Det- N

(III) Det-Gen- N, cf. (8):

\footnotetext{
${ }^{4}$ cf. Taylor (1990), Manolessou (2000).
} 
$\begin{array}{lll}\text { th to_n echthro_n } & \text { timo_rian } \\ \text { the the- enemies-gen } & \text { punishment-acc Lys. } 2.16\end{array}$

\section{(IV) Det-N-Det-Gen}

At this period, the definite article comes into general use. Now it is clear that the G-D-N order is derived, and is parallel to the cases of tu Jani to vivlio 'the John-gen the book' discussed in Horrocks \& Stavrou (1987).

Both D-G-N and D-N-G are very common, as the following figures from Manolessou's work suggest.

$\begin{array}{lll} & \text { Postnominal(I) } & \text { Internal } \\ \text { Herodotus } & 35,41 \% & 36,51 \% \\ \text { Thucydides } & 41,37 \% & 38,49 \% \\ \text { Xenophon } & 63,33 \% & 26,66 \% \\ \text { Aristophanes } & 53,85 \% & 26,92 \% \\ \text { Lysias } & 32,7 \% & 55,77 \% \\ \text { Demosthenes } & 20,75 \% & 58,49 \%\end{array}$

Variation in word order depends largely on the type of text. But in general it seems to be the case that subjective genitives prefer pattern (III), while objective genitives pattern (I). All authors show very low percentages for the (IV) position, which is why I leave it aside in my discussion.

One could suggest that the D-Gen-N pattern correlates with other ordering patterns in the language, e.g. the order of $\mathrm{V}$ with respect to $\mathrm{O}$. In other words, at this stage we could be dealing with a language that was $\mathrm{OV}$. Thus the change from Gen-N to $\mathrm{N}$-Gen correlates with the change from OV to VO. However, in CG both GN and NG are found, relative clauses always follow the noun, adjectives precede the noun. It has also been argued that while Homeric Greek was OV, the change to a VO grammar happened already in the pre-classical period (Taylor 1990), although the word order is relatively free. This suggests that texts from Classical period already show a mixed system as far as the position of the genitive with respect to the noun is concerned.

When two genitives occur with the noun, the subjective one is in prenominal position, while the objective one follows, as in (5)-(6) above, repeated here: ${ }^{5}$

(29) hê

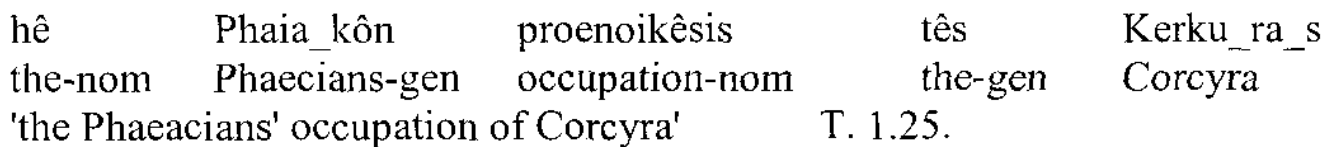

(30) thin

$\begin{array}{llll}\text { thn ge emfrono_n } & \text { zhthsin tou mellontos } \\ \text { the } & \text { wise } & \text { search of the future }\end{array}$

'the search of the future by the wise ones' Pl. Phrd. 224c

According to Manolessou (2000), the internal position is characterized by a number of semantic restrictions. The genitives appearing in this internal position share some common characteristics: they denote human entities, and they must be definite. Frequently they are proper names. The subjective genitive has a clear preference for this position, but the restriction holds for the subjective and objective genitive alike. Note here that possessive

\footnotetext{
${ }^{5}$ The pattern Det-Gensubj-Genobj- Noun- is found only in Thucydides (Manolessou 2000), hence I do not discuss this pattern either.
} 
adjectives in e.g. Slavic, Dutch, German are also limited to proper names (data from de Wit \& Schoorlemmer 1996):

$\begin{array}{llll}\text { Petino } & \text { ispolenenie } & \text { Šopena } & \text { Russian } \\ \text { Petja-PA-N } & \text { performance } & \text { Chopin-gen } & \\ \text { 'Petja's performance of Chopin' } & \end{array}$

De Wit \& Schoorlemmer label 's genitives in Dutch and German PAs as in e.g. Peters Behandlung seiner Mutter 'Peter's treatment of his mother', Jans behandling van de arts 'Johns' treatment of the doctor'. As is the case with CG internal genitive, when both arguments are present the PA bears the agent role:

*Chopin's performance of Petja

In the absence of another genitive the PA in Slavic, German and Dutch can also bear the theme role:

$$
\begin{array}{ll}
\text { Jans } & \text { ontslag } \\
\text { Jan-PA } & \text { dismissa }
\end{array}
$$

Dutch

Unlike PAs in Romance (33) or Slavic, genitives in CG cannot co-occur with adjectives. Examples are rare, and the genitive cannot be assigned a fixed position with respect to the adjective, a fact which led Manolessou (2000) to conclude that the two compete for the same position:

$\begin{array}{lllll}\text { le sue } & \text { goffe } & \text { reazioni } & \text { immediate alla } & \text { tua lettera } \\ \text { the } & \begin{array}{l}\text { his/her clumsy } \\ \text { (Cardinaletti 1998) }\end{array} & \text { reactions } & \text { immediate to-the } & \text { your letter }\end{array}$

In New Testament Greek/Koine, both (A) and (B) are found, but Taylor (1990) points out that the D-Gen-N order is on the decrease, as there are very few cases in Koine Greek.

Table 4

\begin{tabular}{|c|c|c|}
\hline & Classical Greek & Koine Greek \\
\hline $\mathrm{D}-\mathrm{G}-\mathrm{N}$ & $46 \%$ & $2 \%$ \\
\hline$\overline{G-D}-\mathrm{N}$ & $\overline{36 \%}$ & $2 \%$ \\
\hline$\overline{\mathrm{D}-\mathrm{N}-\mathrm{G}}$ & $18 \%$ & $96 \%$ \\
\hline Total & 89 & 102 \\
\hline
\end{tabular}

This is also supported by Manolessou's study, where she states that in this period we observe strong preference for post-nominal position. In the Hellenistic papyri, the internal position is still maintained, with the same semantic restrictions as the ones observed in CG. Manolessou takes the papyri texts to be more reliable, as the New Testament Greek could be argued to be under strong Semitic influence.

In the Byzantine Phase/Mediaeval Greek, again we find both (A) and (B), but in early mediaeval (5-10th c.) texts, pattern (A) is still possible; however, the postnominal position recedes. Internal genitives are still present in the higher registers, even in later centuries. Internal genitives in vernacular texts have been limited to proper names and pronouns. But 
they only appear together with an attributive adjective to support them, as in (34) from Manolessou (2000).

$\begin{array}{llll}\text { (34) ta eugenika tu Halepe } & \text { korasia } \\ \text { the kind-pl the Halepe-gen } & \text { girls }\end{array}$

Only in late texts (14-15th c.) do we establish the complete disappearance of the internal genitive.

In MG only (B) is found, but the presence of an internal genitive is tolerated with clitics in the presence of an adjective only:

(35) i ksafniki tus apohorisi

the sudden their departure

Interestingly, there are a number of semantic restrictions with internal clitics in $\mathrm{MG}$ (Alexiadou \& Stavrou 2000). Consider (36):

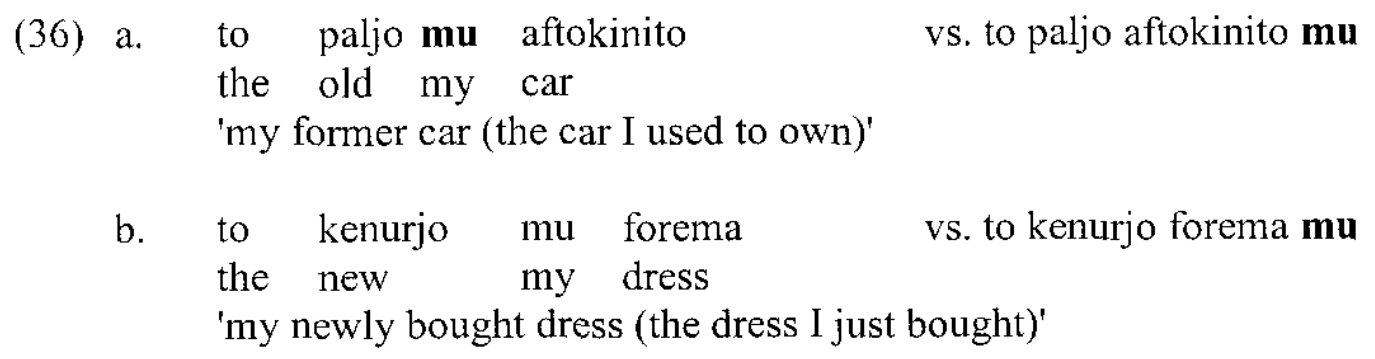

When the clitic is attached to the adjective, it reveals only one of its original meanings. In particular, the adjective paljo ('old') can mean either 'used', 'in bad condition', or formerly possessed; kenurjio ('new') means either newly obtained or in good condition. Both meanings are available when the clitic is postnominal.

Moreover, the authors point out that there is an animacy restriction depending on whether the clitic is attached to the prenominal adjective or to the noun. The post-adjectival position of the clitic then cannot be the same as the post-nominal one, where no such restrictions apply, and it must therefore be located at a different position.
$\begin{array}{llll}\text { a. } & \text { trelos } & \text { odhigos tu } \\ \text { the crazy } & \text { driver- } & \text { it }\end{array}$
'its crazy driver/the crazy driver of the lorry'
b. $*_{0}$ trelos-tu odhigos
the mad-his driver

Alexiadou \& Stavrou (2000) argue that the special interpretation of the clitic is associated with FP in (15b), repeated below, on the specifier of which the adjective is generated. The possessor cliticizes to it. 


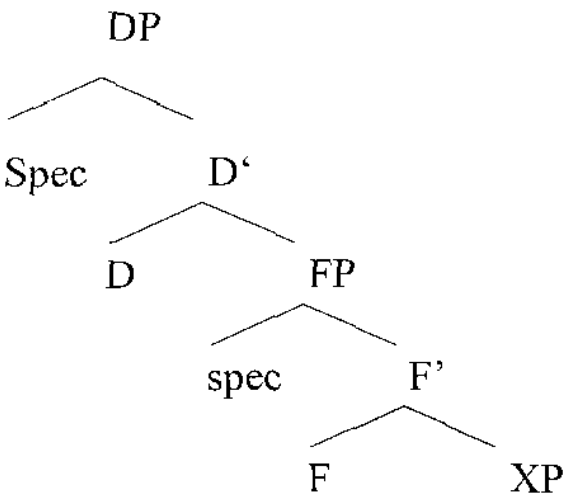

This FP has a similar though not identical function to TP in the sense that it anchors person/animacy features. In some languages, nominal tense does have an overt morphological reflex. Halkomelem, a Salishian language spoken on the Northwest Coast of North America, has overt past tense marking on nouns. The tense marker on nouns is the same as that on verbs. With verbs the past tense marker occurs on a pre-verbal auxiliary, as illustrated in (39a). The same past tense marker $l h$ is also found on Ns as illustrated in (39b-c):
a. i-lh imex tel sí: le aux-past walk my grandfather
'My grandfather walked'
b. tel sí:le
my grandfather
'my grandfather'
c. tel sí: lalh
my grandfather-past
'my late grandfather'

Davis (1998) has argued that the locus of person features is identified as $\mathrm{T}$ in the verbal domain. Following Davis, one could suggest that FP within DP has a similar function. Thus, the temporal readings and the person/animacy restriction are linked with FP, assuming as in Davis (2000) that $T$ in nominals establishes reference and not location in time.

To summarize, the internal position within Greek DPs stops being available for genitive arguments round the 15 th century. MG can tolerate only clitics in this position, as long as there is an adjective to support them. Since in earlier periods the adjective cannot co-occur with a genitive, one can conclude that the adjective in MG and the genitive in earlier stages of Greek occupy the same position, namely FP. The MG clitics, when in internal position, show a number of restrictions similar to the ones observed with the internal genitive in earlier stages of Greek. Hence one can conclude that they are located in the same projection. The following section offers an account of these facts.

\subsection{Accounting for the diachronic change}

In the previous section I argued that FP has a role similar to $\mathrm{TP}$, namely it anchors person/animacy features. Hence I propose that in earlier stages of Greek the genitive argument, irrespective of its function, as well as possessive adjectives across languages, appear in this position. This means that both the clitics in MG and the internal genitive (agent/theme) in CG are associated with the same projection. This view accounts for the semantic restrictions observed both with genitives in $\mathrm{CG}$, and clitics in $\mathrm{MG}$."

\footnotetext{
${ }^{6}$ Manolessou (2000) proposes that genitives in CG and adjectives in MG are located in FP. According to her, FP needs to be identified. This is done either via the genitive in CG, or via the adjective in MG. Manolessou,
} 
In fact this account brings CG nominals close to the analysis of PAs in Slavic proposed in de Wit \& Schoorlemmer (1996). Note here that CG had PAs (40), which are also arguably located in FP in agreement with the remarks made in sections 3.2, and 4.2:

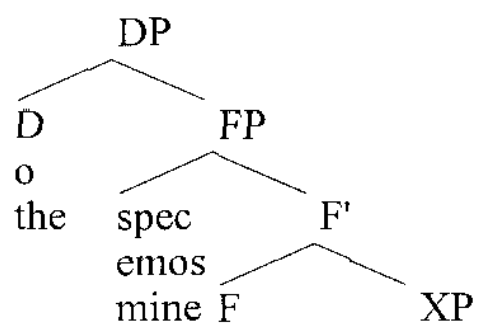

Two questions remain. First, why does this position not host phrasal genitives in MG, since it preserves the residue of the CG system? Second, how does MG and CG differ from English?

Concerning the first issue, clearly the semantic features/function associated with FP remain intact, as is shown by the use of clitics in MG. In order to account for the ban on phrasal, non-agreeing, elements, I examine some related changes in the nominal system of Greek.

The determiner becomes a clitic element, which is in itself in need of a host. While in CG the determiner could host second position particles, as seen in some of the examples here, e.g. (4)-(5), this is no longer possible. In other words the determiner is merely an agreement marker. This change may have triggered a ban on the presence of phrasal non-agreeing elements, with the exception of adjectives. A related change occurs in the possessive system. Note that in CG the genitive of the demonstrative, reflexive and reciprocal pronoun stands generally in prenominal position, while the genitive of the weak form of personal pronouns stands in postnominal position. These prenominal genitives are in complementary distribution with the possessive adjectives.

(41) a. to toutou vivlion

his book

b. to vivlion mou
the book my

But two changes occur. First, the development of the weak forms for the third person pronouns takes place: 'auton' $\rightarrow>$ 'ton'. The formation of the reduced/weak forms of pronouns (clitics) continues and is completed in the Byzantine period. Second, the decline of the use of the possessive adjective which is replaced by the weak form of personal pronouns for all persons: mou 'my', sou 'your' and tou 'his'. In a system such as the one put forth in Cardinaletti \& Starke (1999) whenever there is a choice between a so called weak element, which (certain) possessive adjectives arguably are (see Cardinaletti 1998), and a clitic the clitic form is always preferred. This entails that the development of the possessive clitics has as a result that these replace the possessive adjectives.

Given that these elements become clitics, they need a host. Since they are specified as enclitics, they need to cliticize on an element that can function as a host. Clearly, the determiner does not qualify as such, since it has become a clitic itself. One could imagine that the condition specifying the host of the (poss.) clitic is related to morphological properties

however, does not discuss the properties of internal clitics in MG, which reflect the CG system. Moreover, FP is not always filled, that is DPs without clitics and adjectives also occur, e.g. to vivlio 'the book'. If FP were subject to an identification requirement, it is not clear how it would be identified in such cases. 
along the lines proposed in Sadock (1991), especially if the properties are related with definiteness/animacy.

(42) $X$ may be $X$-cl only if $X=X-Q g e n d e r / n u m b e r$

This means that they can either cliticize on the head nominal as in (37a) or they can cliticize on the adjective as in (36a). The internal position is not possible for the clitic, unless an element is present that satisfies the condition in (42). Since Romance and Slavic do have PAs, they can still form transitive nominalizations of the type described above for CG.

Second, the morphology-syntax of process nominals changed. First, in Koine the endings - ma/mo forming verbal nouns are very much preferred. In fact in early Byzantine period, during the 5th and 6th century, the new deverbative suffix -simo is on the rise replacing -si nouns and the articulate infinitive. (S) $m$ - is a suffix which could be seen as related to middle/passive formation. We find the same suffix in passive participle formation e.g. -menos (note that middle at the time of New Testament Greek starts collapsing morphologically with the passive). As a result, nominal formations are generally interpreted as passive, something that helps avoiding the transitive counterpart within the nominal, and construct strings which are similar to verbal passives. Second, Koine shows a general preference for the use of prepositional phrases which take over functions of the grammatical cases, e.g. the partitive genitive is now expressed via a prepositional phrase. The same holds also for datives denoting the agent. Moreover, the use of genitive declines in general. As a result, agents are projected noun internally in the hypo $+\mathrm{gen} / \mathrm{apo}+\mathrm{acc}$ form necessarily.

Now how is CG and MG different from English? Recall the analysis of English transitive nominals. They include genitives in Spec, DP. Evidence that the genitive is in Spec,DP and not in Spec,FP, as Pesetsky \& Torrego (2000) propose, comes from the fact that English genitives, unlike Slavic PAs, and CG genitives do not show the same semantic restrictions. Hence strings like yesterday's journal etc. are possible in English but not in e.g. Slavic. If the semantic restrictions on internal genitives are related to the feature specification of FP this means English genitives make use of Spec,DP, which is not subject to such restrictions. Note that person/animate genitives could be generated/located at some stage in the derivation in Spec,FP even in English, but they necessarily move to Spec,DP (see Schoorlemmer 1998 for discussion). Otherwise, English could be argued to lack Spec,FP altogether.

\section{Summary}

In this paper I examined a word order change within Greek nominalizations. The relevant change is repeated below:

(A) i) Det-(Genagent)-Nprocess-Gentheme / ii) Det-Gentheme-Nprocess

(B) Det-Nprocess-Gentheme (PPagent)

It was shown that in $\mathrm{CG}$ the genitive preceding the head noun occupied a position external to the NP labeled FP here. Changes in the syntax of the possessive system had as a result that this position is only occupied by agreeing elements, namely adjectives. This in connection with the changes in the determiner system blocks the prenominal and post-determiner position for the argumental genitive. 


\section{References}

Alexiadou, Artemis (1997): Adverb Placement: A Case Study in Antisymmetric Syntax. Amsterdam: John Benjamins.

-- (1999): On the Syntax of Nominalization and Possession: Remarks on Patterns of Ergativity. Habilitationsschrift, University of Potsdam.

-- (2001): Functional Structure in Nominals: Nominalization and Ergativity. Amsterdam: John Benjamins.

--/ Melita Stavrou (1998): On Derived Nominals in Greek. In: B. Joseph, G. Horrocks, I. Philippaki-Warburton (eds.): Themes in Greek Linguistics II. Amsterdam: John Benjamins, 101-129.

-- (2000): Adjective Clitic Combinations in the Greek DP. In: B. Gerlach \& J. Grijzenhout (eds.): Clitics in Phonology, Morphology and Syntax. Amsterdam: John Benjamins, 63-84.

Borer, Hagit (1993): Parallel Morphology. Ms., University of Massachusetts at Amherst.

(1999): The Form, Forming and Formation of Nominals. Ms., USC.

Cardinaletti, Anna (1998): On the Deficient/Strong Opposition in Possessive Systems'. In: A. Alexiadou, C. Wilder (eds.): Possessors, Predicates and Movement in the DP. Amsterdam: John Benjamins, 17-53.

--/Michal Starke (1999): The Typology of Structural Deficiency: A Case Study of the Three Grammatical Classes. In: H. van Riemsdijk (ed.): Clitics in the Languages of Europe.. Berlin: Mouton de Gruyter, 145233.

Chantraine, Paul (1933): La formation des noms en Grec Ancien.

Cinque, Guilgelmo (1999): Adverbs and Functional Heads. Oxford: Oxford University Press.

Davis, Henry (1998): Person Splits, Phi-features and Temporal Architecture. GLOW Newsletter 40, 83-84.

-- (2000): On Nouns and Nominalizations in Salish. Ms., University of British Columbia.

Embick, David (2000): Features, Syntax and Categories in the Latin Perfect. Linguistic Inquiry 31, 185-230.

Greenberg, Joseph (1963): Some Universals of Grammar with Particular References to the Order of Meaningful Elements. In: Joseph H. Greenberg (ed.): Universals of language. Report of a conference held at Dobbs Ferry, New York, April 13-15, 1961. Cambridge, Mass.: MIT Press.

Grimshaw, Jane (1990): Argument Structure. Cambridge, Mass.: MIT Press.

Hazout, Ilan (1995): Action Nominalizations and the Lexicalist Hypothesis. Natural Language and Linguistic Theory $13,355-404$.

Horrocks, Geoffrey (1997): Greek: A History of the Language and its Speakers. London: Longman.

--/ Melita Stavrou (1987): Bounding Theory and Greek Syntax: Evidence for wh-movement in NP. Journal of Linguistics 23, 79-108.

van Hout, Angeliek/ Tom Roeper (1998): Events and Aspectual Structure in Derivational Morphology. MIT Working Papers in Linguistics 32, 175-220.

Kratzer, Angelika (1994): The Event Argument and the Semantics of Voice. Ms., University of Massachusetts at Amherst.

Manolessou, Io (2000): Greek Noun Phrase Structure: A Study in Syntactic Evolution. Ph.D. Diss. University of Cambridge.

Marantz, Alec (1997): No Escape from Syntax: Don't Try a Morphological Analysis in the Privacy of Your Own Lexicon. Ms., MIT.

Pesetsky, David/Esther Torrego (2000): T-to-C, Movement: Causes and Consequences. To appear in: Michael Kenstowicz, Ken Hale (eds.): A Life in Language. Cambridge, Mass.: MIT Press.

Sadock, J. (1991): Autolexical Syntax. Chicago: University of Chicago Press.

Schoorlemmer, Maaike (1998): Possessors, Articles and Definiteness. In: A. Alexiadou, C. Wilder (eds.): Possessors, Predicates and Movement in the DP. Amsterdam: John Benjamins, 55-86.

Taylor, Ann (1990): Clitics and Configurationality in Ancient Greek. Ph. D. Diss. University of Pennsylvania. de Wit, Petra/Maaike Schoorlemmer (1996): Prenominal Arguments in Russian, German and Dutch. ZASPIL 5, 184-202.

Zubizarreta, Maria-Luisa (1987): Levels of Representation in the Lexicon and in the Syntax. Dordrecht: Foris.

\section{Appendix}

(1) Formation of Process nominals

Generally, the noun is formed via the addition of certain affixes to the stem of the related verb.

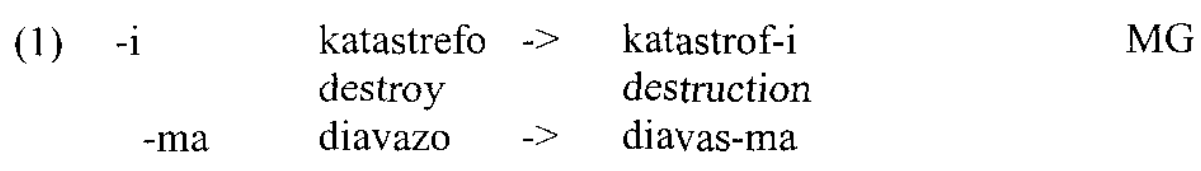




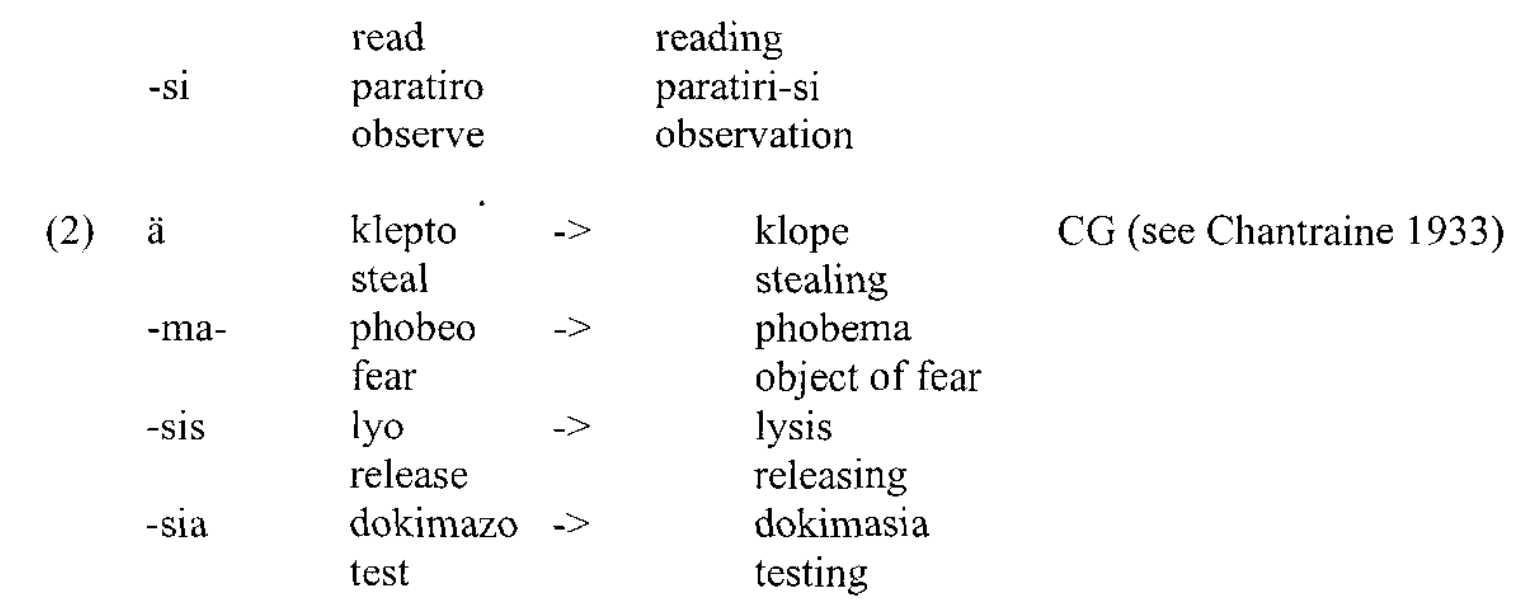

(2) Nominal Structure

In MG never can gender marking be clearly dissociated from number or, for this matter, case marking:

(3) a. anthrop-os

man-ms:sg:nom

b. anthrop-i

man-ms:pl:nom

Similarly in CG:

(4) a. he hodos

the street-fm.nom.sg.

b. tes hodous

the street-fm.gen.sg

This contrasts with e.g. Spanish:

(4) muchach-o(-s) 'boys' muchach-a(-s) 'girls'

The situation supports an analysis according to which Greek nominal architecture contains one and Spanish two nominal functional projections below D:
(5)
a. $\quad[\mathrm{D}[\mathrm{FP} \ldots$
Greek
b. $\quad[\mathrm{D}[\mathrm{FP}[\mathrm{FP} \ldots$
Romance 